\title{
Hip and thigh muscular activity in professional soccer players during an isometric squat with and without controlled hip contraction \\ Actividad muscular de cadera y muslo en jugadores de fútbol profesionales durante una sentadilla isométrica con y sin contracción controlada de cadera

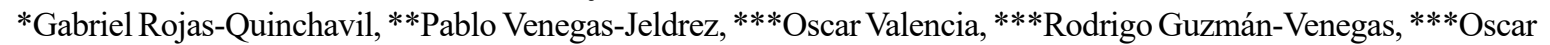 \\ Florencio Araneda, ${ }^{* * * *}$ Francisco José Berral de la Rosa, ${ }^{* * *}$ Andres Felipe Flores-Leon \\ *Clínica Integramédica (Chile), ** Hospital Clínico Mutual de Seguridad (Chile), ${ }^{* * *}$ Universidad de los Andes (Chile), **** \\ Universidad Pablo de Olavide (España)
}

\begin{abstract}
The purpose of the present investigation was twofold 1) To compare the hip and thigh muscular activity of professional soccer players when performing the isometric squat with and without controlled hip contraction; 2) To determine the muscular relationships that take place during these methods of execution of the exercise. Methods: 11 healthy male professional soccer players, randomly performed three modalities of isometric squat at a $60^{\circ}$ knee flexion: conventional squat (SQ), squat with hip abduction contraction (SQ$\mathrm{ABD}$ ) and squat with hip adduction contraction (SQ-ADD), controlled at 70\% of 1 maximum repetition. The activity of the gluteus medius (GM), tensor fasciae latae (TFL), vastus medialis (VM), vastus lateralis (VL), semitendinosus (ST) and biceps femoris (BF) was obtained through surface electromyography. Hip (GM/TFL), quadriceps (VM/VL) hamstrings (ST/BF), and hamstrings/quadriceps (H/ Q) ratios were analyzed. Results: GM increases in SQ-ABD and SQ-ADD compared to SQ ( $<<.01)$. The TFL, VL, SM and BF muscles have significantly higher activity in SQ-ADD compared to SQ $(\mathrm{p}<.05)$. The VL, VM and BF muscles significantly increase their activity in SQ-ADD compared to SQ-ABD $(\mathrm{p}<0.05)$. GM/TFL, VM/VL and ST/BF do not show significant differences between the three isometric squat methods. The H/Q ratio was higher in SQ-ABD and SQ-ADD compared to SQ ( $<$.01). Conclusion: The squat with hip adduction contraction in a controlled manner increases the muscular activity of the hip and thigh. Performing this combined maneuver can have benefits in sports training and rehabilitation because it increases the H/Q ratio of soccer players.
\end{abstract}

Keywords: Isometric exercise; squat; hip; knee; electromyography; soccer player.

Resumen. El propósito de la presente investigación fue doble: 1) Comparar la actividad muscular de la cadera y el muslo de los futbolistas profesionales cuando realizan sentadillas isométricas con y sin contracción controlada de la cadera; 2) Determinar las relaciones musculares que tienen lugar durante estas modalidades de ejecución del ejercicio. Metodología: 11 jugadores de fútbol profesionales sanos, realizaron al azar tres modalidades de sentadilla isométrica con una flexión de rodilla de $60^{\circ}$ : sentadilla convencional (SQ), sentadilla con contracción de abducción de cadera (SQ-ABD) y sentadilla con contracción de aducción de cadera (SQ-ADD), controladas al 70\% de 1 repetición máxima. La actividad del glúteo medio (GM), el tensor de la fascia lata (TFL), el vasto medial (VM), el vasto lateral (VL), el semitendinoso (ST) y el bíceps femoral (BF) se obtuvo mediante electromiografia de superficie. Se analizaron las relaciones de los músculos de la cadera (GM/TFL), cuádriceps (VM / VL), isquiotibiales (ST/BF) e isquiotibiales/cuádriceps (H/Q). Resultados: GM aumenta en SQ-ABD y SQ-ADD en comparación con SQ ( $<<.01)$. Los músculos TFL, VL, SM y BF tienen una actividad significativamente mayor en SQ-ADD en comparación con $\mathrm{SQ}(\mathrm{p}<.05)$. Los músculos VL, VM y BF aumentan significativamente su actividad en SQ-ADD en comparación con SQ-ABD ( $<$.05). GM/TFL, VM/VL y ST/BF no muestran diferencias significativas entre los tres métodos de sentadilla isométrica. La relación H/Q fue mayor en SQ-ABD y SQ-ADD en comparación con $\mathrm{SQ}$ ( $\mathrm{p}<.01$ ). Conclusión: La sentadilla con contracción de aducción de cadera de manera controlada aumenta la actividad muscular de la cadera y el muslo. La realización de esta maniobra combinada puede tener beneficios en el entrenamiento deportivo y la rehabilitación porque aumenta la relación $\mathrm{H} / \mathrm{Q}$ de los jugadores de fútbol.

Palabras claves: ejercicio isométrico; sentadilla; cadera; rodilla; electromiografía; futbolista.

\section{Introduction}

Knee joint injuries are among the most common injuries in soccer (Bianchi, Veneziani, Cantalice, Notarnicola, \& Tafuri, 2018; Driban, Hootman, Sitler, Harris, \& Cattano, 2017; Leventer, Eek, Hofstetter, \& Lames, 2016). Because this joint is subjected to different loads it can be injured by trauma and by alterations in muscular activity, which can increase the risk of injury (Jimenez-Reyes et al., 2018; Pangrazio \& Forriol, 2016a, 2016b). In addition to the above, the risk of osteoarthritis of the knee increases from two to three times in professional soccer players, independent of the presence of significant trauma in his career (Ali Khan et al., 2018; Fernandes et al., 2018; Spahn, Grosser, Schiltenwolf, Schroter, \& Grifka, 2015).

Fecha recepción: 22-07-20. Fecha de aceptación: 18-09-20 Andres Felipe Flores-Leon

aflores@uandes.cl
Due to the functional interdependence that exists between the knee and hip, it is no coincidence that both segments complement each other during training or in the rehabilitation of the lower extremity (Babadi et al., 2018; Barton et al., 2014; Beers, Ryan, Kasubuchi, Fraser, \& Taunton, 2008; Cheatham, Stull, Fantigrassi, \& Montel, 2018; Cichanowski, Schmitt, Johnson, \& Niemuth, 2007; Dix, Marsh, Dingenen, \& Malliaras, 2018; Fredericson et al., 2000; Ireland, Willson, Ballantyne, \& Davis, 2003; Robinson \& Nee, 2007; Rowe et al., 2007; Yu, Shao, Baker, \& Gu, 2018). The evidence is consistent in demonstrating that both hip strengthening and neuromuscular exercise has a beneficial effect on the painful symptomatology of the knee (Hislop, Collins, Tucker, Deasy, \& Semciw, 2019; Thomson, Krouwel, Kuisma, \& Hebron, 2016). Part of this can be explained by the greater activity of the stabilizer muscles of the knee when the hip muscles are activated (Bevilaqua-Grossi, Monteiro-Pedro, de Vasconcelos, Arakaki, \& Bérzin, 2006; Chen, Chang, Wu, \& Fong, 2018; Motomura et al., 2019; Stastny et al., 2015). 
At present, the squat is one of the most used exercises, both to train and to evaluate the strength and explosiveness of the lower limb, because it replicates functional activities and generates an increase of strength in the muscles of the hip and knee (Bazyler, Beckham, \& Sato, 2015; Drake, Kennedy, \& Wallace, 2018; Millán et al., 2014). For this reason, the squat has been studied in different execution methods, including isometric execution (Brady, Harrison, Flanagan, Haff, \& Comyns, 2018; Eliassen, Saeterbakken, \& van den Tillaar, 2018; Raya-González, Piqueras, \& Sánchez-Sánchez, 2018; Van Hooren \& Zolotarjova, 2017). Isometric exercises have shown similar results as plyometric exercises, both in isometric force production and concentric performance (Burgess, Connick, Graham-Smith, \& Pearson, 2007). In addition, the isometric squat has been used as a tool to decrease knee pain (Lim \& Wong, 2018; Rio, Purdam, Girdwood, \& Cook, 2019). The execution of the squat at $60^{\circ}$ of knee flexion is identified as an optimal position for the treatment of anterior knee pain, since it produces a greater activity of the stabilizer muscles and reduces the compression and shear force of this joint (Escamilla, 2001; Tang et al., 2001). Over the years, there has been increased interest in identifying the effect of adding hip movements to the performance of this exercise (Baffa et al., 2012; Earl, Schmitz, \& Arnold, 2001; Hodges \& Richardson, 1993). Hip movements would be associated with neuromuscular control of femoral rotation and increased knee muscle recruitment (Dierks, Manal, Hamill, \& Davis, 2008; Hodges \& Richardson, 1993; Powers, 2003).

Coqueiro et al., (2005), identify that the isometric squat performed with a contraction of adduction of the hip enhances the activity of oblique vastus medialis (VM) and the vastus lateralis (VL) both in asymptomatic people and in patellofemoral pain syndrome. However, the squats were executed in $4^{\circ}$ semiflexion and the muscular activity of the hip was not identified, which is where the adduction force comes from. For their part, Felicio, Dias, Silva, Oliveira, \& Bevilaqua-Grossi, (2011), found a greater myoelectric activity of the VM and the gluteus medius (GM) during the execution of the squat with hip adduction, in sedentary healthy women. Subsequently, this author identified in women with and without patellofemoral pain, that the squat with hip adduction compared with a conventional squat, generates greater activity of the GM in both groups and no differences for the quadriceps muscle were observed between the squats (Felicio, de Carvalho, Dias, \& Vigário, 2019). A similar protocol was used by Hae-rim, Jeong-ah, One-bin, Heon-seock, \& Chunghwi, (2015), with the objective of identifying the muscular activity of the GM and the tensor fasciae latae (TFL) in healthy men and women, concluding that while both the abduction and the adduction of the hip produce greater activity of both muscles, the GM/TFL ratio was greater during the execution of the squat with hip adduction. The aforementioned studies perform the squat with the person's back supported by a wall, adding an additional load of $25 \%$ of body weight, intensifying the myoelectric activity of the GM. On the other hand, Hyong, (2015) identifies that during the execution of the squat without dorsal support, there is a greater $\mathrm{VM} / \mathrm{VL}$ ratio when performing this exercise with hip adduction compared with no hip contraction, however once again the level of muscular activity of this joint is not identified, nor is the intensity of force exerted by the hip controlled.

Although the literature has reported the activity of the hamstrings during the execution of the squat (Contreras, Vigotsky, Schoenfeld, Beardsley, \& Cronin, 2016; McCurdy, Walker, \& Yuen, 2018; Wu, Tsai, Liang, \& Chang, 2019), the level of muscular activity of these muscles when performing the exercise with hip abduction and adduction in a controlled manner is currently unknown. Understanding the muscular behavior of the back of the thigh and its relationship with the coactivation of the hamstrings could facilitate the choice of this exercise in the training and rehabilitation of the lower extremity.

Due to the fact that the squat is widely used in the training and rehabilitation of the lower limb of soccer players (Dinc, Kilinc, Bulat, Erten, \& Bayraktar, 2017; González, MorenoArrones, Bretones, \& de Villarreal Sáez, 2018; Hammami et al., 2018; Styles, Matthews, \& Comfort, 2016; Suarez-Arrones et al., 2018), to know the effect that the hip contractions produce on the muscular performance of this exercise might be useful for clinicians and coaches linked to this sport. Thus, the purpose of the present investigation was twofold: 1) To compare the hip and thigh muscular activity of professional soccer players when performing the isometric squat with and without controlled hip contraction; 2) To determine the muscular ratios that take place during these methods of execution of the exercise. Our hypothesis was that the squat with hip contraction produces greater activity of the assessed muscles and that muscular relationships are greater when the squat is performed with an isometric contraction of hip adduction.

\section{Materials \& Methods}

\section{Study Design}

An observational, analytical and cross-sectional study design was used.

\section{Sample description}

The sample size calculation was carried out by means of GPower software (V.3.1.9.2, University of Kiel, Germany), where the data obtained from Hae-rim et al., (2015), was used for the variable percentage of maximal voluntary contraction (\%MVC) of the gluteus medius during the isometric squat $(5.13 \pm 4.01)$ and the isometric squat with hip contraction in adduction (25.91 \pm 17.08$)$, by considering a $95 \%$ power and a significance level of .05, two-tailed. A minimum value of 10 participants was identified. A loss value of $10 \%$ was estimated, therefore, the number of volunteers accounted for was 11 people.

Twelve athletes were evaluated, one of whom was excluded because of an error during data registration which was counted as missing data. The sample corresponded to 11 healthy male professional soccer players, of $19.36 \pm .50$ years old, weighing $66.45 \pm 7.70 \mathrm{~kg}, 173 \pm .06 \mathrm{~cm}$ in height, $\mathrm{BMI}=$ normal and nine being right-leg dominant and two being left-leg dominant athletes. Those athletes who had pain or injury of the trunk or lower extremities in the past two months were excluded; those with surgeries involving the musculoskeletal system over the past year, and those who 
presented discomfort that prevented a correct execution of the test during the assessment were also excluded.

\section{Procedure}

The participants were performed for the sake of convenience. First, the athletes were contacted in the place of training to raise awareness of the research and were invited to freely participate in the study. Subsequently, an appointment was scheduled for the realization of the evaluation procedure, which was carried out during the second half of the year 2018. All measurements were carried out in a session in a biomechanics and movement analysis laboratory, where temperature variations, noise and light variations were controlled.

On evaluation day all athletes signed an informed consent approved by a local ethics committee in accordance with the Declaration of Helsinki(CECSSMO08082017). The exclusion criteria were identified by means of a questionnaire applied by an evaluator. Subsequent to this, anthropometric measurements (weight and height) for the calculation of BMI were carried out. Then another evaluator verbally explained the proper execution of conventional squat (SQ), squat with hip abduction contraction (SQ-ABD) and squat with hip adduction contraction (SQ-ADD). For this, it was indicated and controlled that the trunk remained in an upright position as much as possible during the execution of the exercise. A five minute warm-up on a cycloergometer set to moderate load was conducted before the assessment, determined by the Borg CR10 scale (Borg, 1990). The order of the test executions was randomized. Three repetitions of each squat modality were registered, 30 seconds rests were determined between each evaluation in order to avoid tolerance and the appearance of fatigue.

\section{Assessment of the abductor and adductor hip strength:}

The resistances were determined by a pressure sensor (Bigben ${ }^{\circledR}$, Rudolf Riester GmbH, Jungingen, Germany) inflated to $40 \mathrm{mmHg}$ as a baseline value, located at the end of the distal lateral end of the right thigh for the SQ-ABD and at the end of the distal medial end of the same thigh for the SQADD. The maximum force exerted on the pressure sensor was determined prior to the test execution by means of the valuation of $1 \mathrm{RM}$. Subsequently, 70\% of $1 \mathrm{RM}$ (McBeth, Earl-Boehm, Cobb, \& Huddleston, 2012) was calculated as the force exerted by the participant during the isometric executions of SQ-ABD and SQ-ADD. By means of the visual feedback provided by the pressure sensor clock, the participant was instructed to keep the pressure once he had reached the squat position.

\section{Evaluation of muscular activity:}

The evaluation of muscular activity was performed with a 16-channel Bagnoli surface electromyograph (Delsys ${ }^{\circledR}$, 650 Beacon St. Boston MA 02215, USA). Prior to the placement of the electrodes, the skin was prepared by shaving and cleaning with $90 \%$ denatured alcohol to reduce the impedance of the area for evaluation. Subsequently, bipolar surface electrodes were placed (2.1, DELSYS Inc. Natick MA, USA) on the right lower limb, on the muscles gluteus medius (GM), tensor fasciae latae (TFL), vastus medialis (VM), vastus lateralis (VL), semitendinosus (ST) and biceps femoris (BF), considering the SENIAM recommendations (Hermens, Freriks, Disselhorst-Klug, \& Rau, 2000) (Figure 1-A). In addition, a reference electrode was placed in the spinous process of C7.

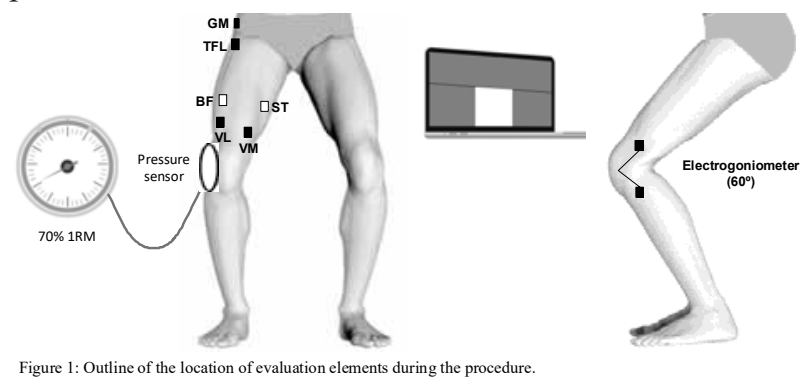

A: Location of the electrodes. Black is used to represent markers in a previous view, white is used to represent the markers in an overlapping manner. This diagram shows the pressure sensor located on the lateral side of the right knee. B: Placement of the electrogoniometer on the side of the left knee, which determined the degree of knee flexion means of a feedback toolbar.

An electrogoniometer placed on the side of the left knee was used. There was a toolbar for visual feedback attached to $60^{\circ}$ knee flexion (Figure 1-B) (Tang et al., 2001). The evaluated soccer player was instructed to reach this angle during the first 3 seconds of the test and then to maintain the evaluated squat method for 8 seconds, with a 30 second rest period between each test.

At the end of the evaluation of the exercises, a maximum voluntary contraction (MVC) for each of the evaluated muscles was performed. To ensure that the possible local muscle fatigue did not affect the performance of the MVC, this evaluation was carried out five minutes after the last execution of the squat (Waly, Asfour, \& Khalil, 2003).

The signals obtained from the muscles were sampled with a sampling frequency of $1000 \mathrm{~Hz}$ and captured by means of an EMGworks software (V.4.0. Delsys. Boston. MA. USA). Then a computer macro was used (Igor Pro 6.37. WaveMetrics. OR. USA.), where the rectified signal was processed with a low pass of $20 \mathrm{~Hz}$, fourth-order Butterworth filter (Valencia et al., 2020). The analysis window corresponded to the 3 intermediate seconds from the start of the isometric maintaining of the squat. Electrical muscle activity was calculated based on the root mean square of the captured signal. Finally, the data were expressed as a percentage of the maximum voluntary contraction.

\section{Description of the tests}

Conventional Squat (SQ) (Figure 2-A)

The athlete adopted a bipedal position, with feet placed shoulder-width apart and hands placed on his shoulders. He then completed a $60^{\circ}$ knee flexion, which had to be isometrically maintained.

Squat with Hip Abduction (SQ-ABD) (Figure 2-B)

The athlete adopted a bipedal position, with feet placed shoulder-width apart and hands placed on his shoulders. He then performed a $60^{\circ}$ knee flexion, with a resisted hip abduction movement aimed at separating both knees, which had to be maintained isometrically. The lateral resistance opposed to the hip abduction was granted by a rigid tape attached to the pressure sensor.

Squat with Hip Adduction (SQ-ABD) (Figure 2-C)

The athlete adopted a bipedal position, with feet placed shoulder-width apart and hands placed on his shoulders. Then he performed a $60^{\circ}$ knee flexion with a resisted hip 
abduction movement aimed at separating both knees, which had to be maintained isometrically. The medial resistance opposed to the hip abduction was granted by a rigid device attached to the pressure sensor.

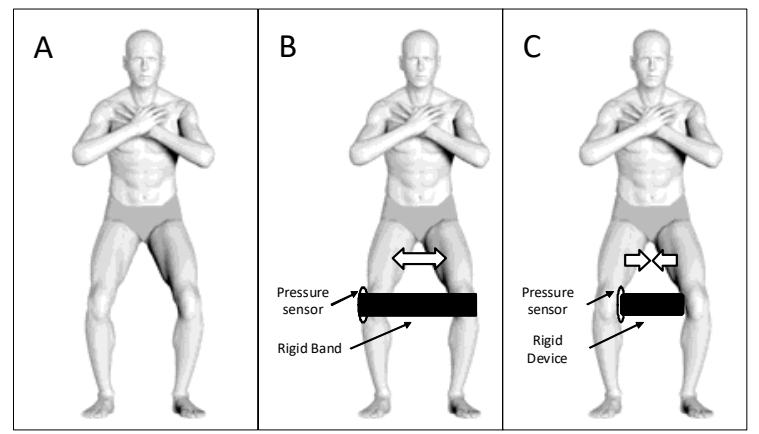

Figure 2: Isometric squat execution methods

A: Conventional Squat (SQ). B: Squat with Hip Abduction (SQ-ABD). C: Squat with Hip adduction (SQ-ADD). The diagram shows the location of the pressure sensor and the devices used to generate resistance.

\section{Statistical Analysis}

The average of the three repetitions of each of the squat methods was used for each study participant. These data were grouped in SQ, SQ-ABD, and SQ-ADD.

The Shapiro-Wilks test was applied for statistical analysis to identify the distribution of data normality. For each comparison, a one-way variance analysis (ANOVA) was used for repeated measurements, with a subsequent Tukey test to identify significant differences between the evaluated squat executions. A significance level of $\mathrm{p}<.05$ was considered for all results. Statistical calculations were performed with Prism 6 software (GraphPad Software, California, USA.).

The analysis consisted of comparing the results of each muscle in the three methods of isometric squat. Subsequently, the hip abductor muscles (GM/TFL), quadriceps (VM/VL), hamstrings $(\mathrm{ST} / \mathrm{BF})$ and the hamstrings/quadriceps ratio $(\mathrm{H} /$ $\mathrm{Q}=[\mathrm{ST}+\mathrm{BF}] /[\mathrm{VM}+\mathrm{VL}])$, were grouped by ratios in order to analyze co-contraction during the execution of the three squat methods. The data presented correspond to 11 evaluated athletes.

\section{Results}

Comparison of muscular activity according to isometric squat modality showed that GM increases on SQ-ABD and $\mathrm{SQ}-\mathrm{ADD}$ relative to $\mathrm{SQ}(\mathrm{p}<.01)$. TFL, VL, $\mathrm{SM}$, and BF muscles

Table 1:

Hip and thigh muscle activity comparison during isometric execution of the squats.

\begin{tabular}{ccccccccc}
\hline & Conventional $95 \%$ confidence & \multicolumn{3}{c}{ Squat with } & \multicolumn{5}{c}{$95 \%$ confiden } & \multicolumn{4}{c}{ Squat with Hip $95 \%$ confidenc ANOVA p- } \\
& Squat & interval & Hip Abduction & ce interval & Adduction & e interval & value \\
\hline Gluteus medius & $2.02 \pm .91$ & 1.41 to 2.63 & $7.67 \pm 4.08^{*}$ & 4.93 to 10.41 & $12.40 \pm 4.84^{*}$ & 9.15 to 15.65 & $<.01$ \\
Tensor fasciae latae & $2.96 \pm 2.17$ & 1.50 to 4.41 & $7.02 \pm 5.04$ & 4.63 to 10.41 & $7.78 \pm 2.86^{*}$ & 5.86 to 9.70 & .02 \\
Vastus medialis & $13.67 \pm 8.42$ & 8.13 to 19.33 & $9.69 \pm 6.00$ & 5.66 to 13.72 & $15.93 \pm 6.79 \dagger$ & 8.13 to 20.49 & $<.01$ \\
Vastus lateralis & $10.32 \pm 2.92$ & 8.35 to 12.28 & $8.80 \pm 2.79$ & 6.93 to 10.68 & $12.19 \pm 3.08^{*} \dagger$ & 10.12 to 14.25 & $<.01$ \\
Semitendinosus & $2.48 \pm 1.91$ & 1.19 to 3.76 & $3.81 \pm 3.24$ & 1.64 to 5.99 & $5.45 \pm 3.46^{*}$ & 3.13 to 7.77 & .03 \\
Biceps femoris & $5.86 \pm 4.54$ & 2.81 to 8.91 & $6.27 \pm 4.27$ & 3.41 to 9.14 & $10.71 \pm 5.35^{* \dagger} 7.12$ to 14.31 & $<.01$ \\
\hline
\end{tabular}

Table 2:

Hip and thigh ratios comparison during squats execution.

\begin{tabular}{cccccccc}
\hline & $\begin{array}{c}\text { Conventional } \\
\text { Squat }\end{array}$ & $\begin{array}{c}95 \% \text { confidence } \\
\text { interval }\end{array}$ & $\begin{array}{c}\text { Squat with Hip } \\
\text { Abduction }\end{array}$ & $\begin{array}{c}95 \% \text { confidence } \\
\text { interval }\end{array}$ & $\begin{array}{c}\text { Squat with Hip } \\
\text { adduction }\end{array}$ & $\begin{array}{c}95 \% \text { confidence } \\
\text { interval }\end{array}$ & $\begin{array}{c}\text { ANOVA } \\
\text { p-value }\end{array}$ \\
\hline $\mathrm{GM} / \mathrm{TFL}$ & $1.14 \pm 1.14$ & .37 to 1.91 & $1.54 \pm 1.10$ & .81 to 2.29 & $1.76 \pm 0.89$ & 1.16 to 2.29 & .37 \\
$\mathrm{VM} / \mathrm{VL}$ & $1.28 \pm .59$ & .89 to 1.68 & $1.12 \pm 0.54$ & .76 to 1.49 & $1.33 \pm 0.52$ & .99 to 1.69 & .28 \\
$\mathrm{ST} / \mathrm{BF}$ & $1.09 \pm 1.68$ & -.04 to 2.22 & $.95 \pm 1.02$ & .26 to 1.63 & $.79 \pm .96$ & .15 to 1.43 & .63 \\
$\mathrm{H} / \mathrm{Q}$ & $.39 \pm 2.24$ & .23 to 0.55 & $.63 \pm 0.40^{*}$ & .36 to 0.90 & $.63 \pm .32^{*}$ & .41 to 0.84 & $<.01$ \\
\hline
\end{tabular}

The data shows the mean and standard deviation of 11 participants. The data are expressed as the ratio of the percentage of the maximum voluntary contraction of the indicated muscles.GM/TFL = gluteus medius:tensor fasciae latae; VM/VL = vastus medialis:vastus lateralis; $S T / B F=$ semitendinosus:biceps femoris; $H / Q=$ hamstring:quadriceps. ${ }^{*}=$ Different to Conventional Squat. have significantly greater activity on SQ-ADD compared to $\mathrm{SQ}(\mathrm{p}<.05)$. In turn, it was noted that VL, VM and BF muscles significantly increase their activity on SQ-ADD compared to SQ-ABD $(\mathrm{p}<.05)$. The comparison data of muscular activity according to squat modalities are shown in Table 1.

In regards to the ratio of muscular groups in the hip and thigh (GM/TFL; VM/VL and ST/BF) no significant differences were found in relation to the three isometric squat methods. The $H / Q$ ratio was significantly higher in the execution of the isometric squat with SQ-ABD and with SQ-ADD in relation to $\mathrm{SQ}(\mathrm{p}<.01)$. The data from the comparison of muscle ratios are shown in Table 2.

\section{Discussion}

This study compared muscle behavior of the hip and thigh of professional soccer players when performing the isometric squat with and without hip muscle contraction. Differences in the levels of muscle activation and their relations of force were reported when performing the squat with hip contraction in both abduction and adduction. These findings relate to those previously reported, where it is demonstrated that the squat with hip contraction modifies the muscular activity of the hip and thigh (Coqueiro et al., 2005; Felicio et al., 2011; Hae-rim et al., 2015).

\section{Muscular activity of the hip}

In relation to the behavior of the hip abductor muscles, there is greater GM activity in both SQ-ABD and SQ-ADD in relation to SQ. This finding is consistent with what was previously reported by other authors (Felicio et al., 2011; Hae-rim et al., 2015), who explain that this muscle would respond to medial and lateral hip contractions to facilitate pelvic stability and to eccentrically control the internal rotation of the hip during hip flexion positions (Kim, Unger, Lanovaz, \& Oates, 2016; Willcox \& Burden, 2013).

For its part, TFL muscular activity only increases significantly during SQ-ADD compared to SQ. These results differ to those reported by Hae-rim et al., (2015), who identify that both hip contractions increase the activity of TFL compared to the conventional execution of this exercise. Although the synergistic action of this muscle in hip abduction and pelvis stabilization has been reported (Trammell \& Pilson, 2019), our data suggest that TFL acts as a hip adduction stabilizer when a controlled contraction of this joint is performed (70\% 1RM). On the other hand, recent studies have identified that hip position affects TFL activity; however, these reports use decubitus positions (Fujisawa et al., 2014; Park \& Cho, 2016). Possibly, the results of the present investigation could be determined by the position adopted by the athlete when performing a squat without back support, which would modify the position of the hip. More studies are needed to analyze the action of the TFL in different hip positions during squat execution, as well as in different 1RM percentages of this exercise. 


\section{Thigh muscular activity}

Regarding extensor muscles of the knee, the data obtained in this study indicate that VM significantly increases its activity when SQ-ADD was compared with SQ$\mathrm{ABD}$, while VL produces a higher level of activation in SQADD compared with SQ-ABD and SQ. Similar results have previously been reported in relation to the increased activity that occurs in VM and VL during a squat with hip adduction compared to normal execution (Coqueiro et al., 2005; Miao, Xu, Pan, Liu, \& Wang, 2015). For its part, the study indicates that VM activity is greater when a squat is performed with SQ-ADD compared to SQ-ABD, a condition that was also observed in our work. However, these authors report that VL increases its activation levels in both the squat with hip abduction and in the squat with hip adduction compared to a conventional squat. It is possible that the differences observed between both studies are because, in the current study, SQ-ABD was reported to show the lowest activity levels of both vasti.

On the other hand, in relation to what is observed in the muscles of the posterior area of the thigh, it stands out that the activity of ST is greater in SQ-ADD compared to SQ whereas in $\mathrm{BF}$ this exercise produces a greater activity compared with SQ and SQ-ABD. Nishiwaki, Urabe, \& Tanaka, (2006), identifies that ST does not modify its activity level during a conventional dynamic squat, so our results suggest that the combined action of the squat and hip contraction can be used in the progressive training of this muscle. Specifically, this finding can be used by trainers and rehabilitators of the lower limb, since the ST helps the popliteal muscle to stabilize the rotation of the knee and controls this joint during the squat (Mathew \& Pillarisetty, 2020; Nishiwaki et al., 2006). Therefore, adding an isometric contraction of the hip to the squat would allow an increase in ST activity, avoiding a knee rotation mechanism associated with the injury (Barra, Cabezas, \& Gajardo, 2020; Madueño, de Hoyo Lora, Boza, Cortés, \& Corrales, 2014; Navacchia, Bates, Schilaty, Krych, \& Hewett, 2019; Wada, Gamada, Aoyama, Mizuno, \& Iwasaki, 2019).

The results observed in BF could be due to the fact that this muscle would control both the eccentric contraction of hip adduction and knee stability (Flaxman, Alkjaer, Simonsen, Krogsgaard, \& Benoit, 2017), being able to act as a synergist of hip-pelvis and hip-knee stability in the frontal plane so new studies must be carried out to verify this action. In addition, the activity presented by these muscles may be due to the action of counteracting the activation of quadriceps, acting as synergists of knee ligaments to maintain joint stability (Baratta et al., 1988; Flores-León, Alonso, Guzmán-Venegas, Araneda, \& Berral de la Rosa, 2018). Because this is the first report that identifies the behavior of the hamstrings during an isometric squat with hip contractions the findings obtained in this paper can be used as a basis for further research.

\section{Hip and thigh muscular ratios}

In the present investigation, no differences were found in the synergistic relationships of the hip muscle groups (GM/TFL), the quadriceps (VM/VL) or the hamstrings (ST/ $\mathrm{BF})$. However, other authors have identified significant differences both in VM/VL and GM/TFL when the squat with hip contraction is performed (Hae-rim et al., 2015; Hyong, 2015). Unlike these studies, the present paper is the first to control the force from the hip during the squat so it is possible that the results obtained in this research are related to a greater selectivity of muscular recruitment, which would allow the relationships of synergistic muscular groups to remain similar despite the modification of muscular activity that is produced individually. This finding suggests that controlled hip contraction would facilitate synergistic muscular training in a balanced manner.

It is observed in this investigation that the $\mathrm{H} / \mathrm{Q}$ ratio increases in both SQ-ABD and SQ-ADD when compared to $\mathrm{SQ}$. The imbalance of $\mathrm{H} / \mathrm{Q}$ ratio can affect performance and increase the soccer player's risk of injury (Ardern, Pizzari, Wollin, \& Webster, 2015; Grygorowicz et al., 2017; Lee, Mok, Chan, Yung, \& Chan, 2018). It has been reported that an H/Q ratio is adequate when it has levels equal to or greater than 0.6 because it decreases the risk of injury in the knee, while proportions closer to 1 indicate a greater activation of the hamstrings which helps to increase the stability of this joint (Cheung, Smith, \& Wong del, 2012; Dorgo, Edupuganti, Smith, \& Ortiz, 2012). As in our work, it has been previously reported that the conventional squat shows lower H/Q coactivation rates (Dedinsky, Baker, Imbus, Bowman, \& Murray, 2017). Recent studies have identified that the increase of this ratio can be provided by the eccentric training of muscles of the thigh (Ruas, Brown, Lima, Costa, \& Pinto, 2018) and the angulation of the knees (De Ste Croix, EINagar, Iga, Ayala, \& James, 2017). However, the results of this research suggest that the squat combined with hip contractions can also be used as a muscle training strategy to improve the coactivation of H/Q at adequate levels that avoid the risk of knee injury for these athletes.

There are limitations to this study. First, it only evaluated the position of $60^{\circ}$ knee flexion, so future research should identify the effects of different angulations of the joint during the execution of the squats evaluated. Also, the angle of hip and trunk was not recorded in this work, so the data could be influenced by the position that the athlete adopted. Future research should consider these assessments. In addition, this study considered only healthy soccer players, which could not generalize the results to other groups, so subsequent studies could identify muscle activity in people with lower limb pathologies when performing these three squat methods.

The data provided by this research can be applied by coaches and clinicians seeking to improve the neuromuscular control of the hip and thigh of professional soccer players. The use of the squat maneuver combined with isometric hip forces could promote muscular balance, which would help reduce injuries in these athletes.

\section{Conclusions}

The squat with hip adduction contraction in a controlled manner increases the muscular activity of the hip and thigh. Performing this combined maneuver can have benefits in sports training and rehabilitation because it increases the $\mathrm{H} /$ $\mathrm{Q}$ ratio of soccer players. 


\section{Acknowledgements}

We would like to express our great appreciation to the people who voluntarily participated in this study.

\section{References}

Ali Khan, M. M., Siddiqui, A. A., Yaqoob, U., Yaqub, M. D., Khan, O. J., \& Ul-Haq, F. (2018). Post-football Gonathrosis: Injuries and Surgeries are A Risk. Cureus, 10(7), e2953. doi:10.7759/cureus.2953

Ardern, C. L., Pizzari, T., Wollin, M. R., \& Webster, K. E. (2015). Hamstrings strength imbalance in professional football (soccer) players in Australia. J Strength Cond Res, 29(4), 997-1002. doi:10.1519/jsc.0000000000000747

Babadi, N., Roostayi, M. M., Rahimi, A., Baghban, A. A., Sarmadi, A., \& Roostaei, H. (2018). The effect of different hip rotation angles on electromyography activity of the quadriceps muscle during closed kinetic chain tasks in healthy females. $J$ Phys Ther Sci, 30(8), 1112-1116. doi:10.1589/jpts.30.1112

Baffa, A. P., Felicio, L. R., Saad, M. C., Nogueira-Barbosa, M. H., Santos, A. C., \& Bevilaqua-Grossi, D. (2012). Quantitative MRI of vastus medialis, vastus lateralis and gluteus medius muscle workload after squat exercise: comparison between squatting with hip adduction and hip abduction. J Hum Kinet, 33, 5-14. doi:10.2478/v10078-012-0039-z

Baratta, R., Solomonow, M., Zhou, B. H., Letson, D., Chuinard, R., \& D'Ambrosia, R. (1988). Muscular coactivation. The role of the antagonist musculature in maintaining knee stability. $\mathrm{Am}$ $J$ Sports Med, 16(2), 113-122. doi:10.1177/ 036354658801600205

Barra, C. M. S. M., Cabezas, G. R., \& Gajardo, J. T. (2020). Propuesta de modelo predictivo de lesión en base a descriptores anatómicos y biofuncionales que se relacionan con la inestabilidad articular en rodilla y tobillo en jugadores de baloncesto no profesionales. Retos: nuevas tendencias en educación

física, deporte y recreación(39), 257-263.

Barton, C. J., Kennedy, A., Twycross-Lewis, R., Woledge, R., Malliaras, P., \& Morrissey, D. (2014). Gluteal muscle activation during the isometric phase of squatting exercises with and without a Swiss ball. Phys Ther Sport, 15(1), 39-46. doi:10.1016/j.ptsp.2013.02.006

Bazyler, C. D., Beckham, G. K., \& Sato, K. (2015). The use of the isometric squat as a measure of strength and explosiveness. $J$ Strength Cond Res, 29(5), 1386-1392. doi:10.1519/ jsc.0000000000000751

Beers, A., Ryan, M., Kasubuchi, Z., Fraser, S., \& Taunton, J. E. (2008). Effects of Multi-modal Physiotherapy, Including Hip Abductor Strengthening, in Patients with Iliotibial Band Friction Syndrome. In Physiother Can (Vol. 60, pp. 180-188).

Bevilaqua-Grossi, D., Monteiro-Pedro, V., de Vasconcelos, R. A., Arakaki, J. C., \& Bérzin, F. (2006). The effect of hip abduction on the EMG activity of vastus medialis obliquus, vastus lateralis longus and vastus lateralis obliquus in healthy subjects. In $J$ Neuroengineering Rehabil (Vol. 3, pp. 13).

Bianchi, F. P., Veneziani, V., Cantalice, M. A., Notarnicola, A., \& Tafuri, S. (2018). Epidemiology of injuries among Italian footballers: the role of the playing field. Inj Prev. doi:10.1136/ injuryprev-2018-042968

Borg, G. (1990). Psychophysical scaling with applications in physical work and the perception of exertion. Scand J Work Environ Health, 16 Suppl 1, 55-58.

Brady, C. J., Harrison, A. J., Flanagan, E. P., Haff, G. G., \& Comyns, T. M. (2018). A Comparison of the Isometric Midthigh Pull and Isometric Squat: Intraday Reliability, Usefulness, and the Magnitude of Difference Between Tests. Int J Sports Physiol
Perform, 13(7), 844-852. doi:10.1123/ijspp.2017-0480

Burgess, K. E., Connick, M. J., Graham-Smith, P., \& Pearson, S. J. (2007). Plyometric vs. isometric training influences on tendon properties and muscle output. Journal of strength and conditioning research, 21(3), 986.

Cheatham, S. W., Stull, K. R., Fantigrassi, M., \& Montel, I. (2018). Hip Musculoskeletal Conditions and Associated Factors That Influence Squat Performance: A Systematic Review. J Sport Rehabil, 27(3), 263-273. doi:10.1123/jsr.2016-0246

Chen, S., Chang, W. D., Wu, J. Y., \& Fong, Y. C. (2018). Electromyographic analysis of hip and knee muscles during specific exercise movements in females with patellofemoral pain syndrome: An observational study. Medicine (Baltimore), 97(28), e11424. doi:10.1097/md.0000000000011424

Cheung, R. T., Smith, A. W., \& Wong del, P. (2012). H:q ratios and bilateral leg strength in college field and court sports players. $J$ Hum Kinet, 33, 63-71. doi:10.2478/v10078-012-0045-1

Cichanowski, H. R., Schmitt, J. S., Johnson, R. J., \& Niemuth, P. E. (2007). Hip strength in collegiate female athletes with patellofemoral pain. Med Sci Sports Exerc, 39(8), 1227-1232. doi:10.1249/mss.0b013e3180601109

Contreras, B., Vigotsky, A. D., Schoenfeld, B. J., Beardsley, C., \& Cronin, J. (2016). A Comparison of Gluteus Maximus, Biceps Femoris, and Vastus Lateralis Electromyography Amplitude in the Parallel, Full, and Front Squat Variations in ResistanceTrained Females. J Appl Biomech, 32(1), 16-22. doi:10.1123/ jab.2015-0113

Coqueiro, K. R., Bevilaqua-Grossi, D., Berzin, F., Soares, A. B., Candolo, C., \& Monteiro-Pedro, V. (2005). Analysis on the activation of the VMO and VLL muscles during semisquat exercises with and without hip adduction in individuals with patellofemoral pain syndrome. J Electromyogr Kinesiol, 15(6), 596-603. doi:10.1016/j.jelekin.2005.03.001

De Ste Croix, M., ElNagar, Y. O., Iga, J., Ayala, F., \& James, D. (2017). The impact of joint angle and movement velocity on sex differences in the functional hamstring/quadriceps ratio. Knee, 24(4), 745-750. doi:10.1016/j.knee.2017.03.012

Dedinsky, R., Baker, L., Imbus, S., Bowman, M., \& Murray, L. (2017). Exercises that facilitate optimal hamstring and quadriceps co-activation to help decrease acl injury risk in healthy females: a systematic review of the literature. Int $J$ Sports Phys Ther, 12(1), 3-15.

Dierks, T. A., Manal, K. T., Hamill, J., \& Davis, I. S. (2008). Proximal and distal influences on hip and knee kinematics in runners with patellofemoral pain during a prolonged run. $J$ Orthop Sports Phys Ther, 38(8), 448-456. doi:10.2519/ jospt.2008.2490

Dinc, E., Kilinc, B. E., Bulat, M., Erten, Y. T., \& Bayraktar, B. (2017). Effects of special exercise programs on functional movement screen scores and injury prevention in preprofessional young football players. J Exerc Rehabil, 13(5), 535-540. doi:10.12965/jer.1735068.534

Dix, J., Marsh, S., Dingenen, B., \& Malliaras, P. (2018). The relationship between hip muscle strength and dynamic knee valgus in asymptomatic females: A systematic review. Phys Ther Sport. doi:10.1016/j.ptsp.2018.05.015

Dorgo, S., Edupuganti, P., Smith, D. R., \& Ortiz, M. (2012). Comparison of lower body specific resistance training on the hamstring to quadriceps strength ratios in men and women. Res Q Exerc Sport, 83(2), 143-151. doi:10.1080/ 02701367.2012.10599844

Drake, D., Kennedy, R., \& Wallace, E. (2018). Familiarization, validity and smallest detectable difference of the isometric squat test in evaluating maximal strength. J Sports Sci, 36(18), 20872095. doi: $10.1080 / 02640414.2018 .1436857$

Driban, J. B., Hootman, J. M., Sitler, M. R., Harris, K. P., \& 
Cattano, N. M. (2017). Is Participation in Certain Sports Associated With Knee Osteoarthritis? A Systematic Review. J Athl Train, 52(6), 497-506. doi:10.4085/1062-6050-50.2.08

Earl, J. E., Schmitz, R. J., \& Arnold, B. L. (2001). Activation of the $\mathrm{VMO}$ and $\mathrm{VL}$ during dynamic mini-squat exercises with and without isometric hip adduction. J Electromyogr Kinesiol, 11(6), 381-386.

Eliassen, W., Saeterbakken, A. H., \& van den Tillaar, R. (2018). Comparison of bilateral and unilateral squat exercises on barbell kinematics and muscle activation. Int J Sports Phys Ther, 13(5), 871-881.

Escamilla, R. F. (2001). Knee biomechanics of the dynamic squat exercise. Med Sci Sports Exerc, 33(1), 127-141.

Felicio, L. R., de Carvalho, C. A. M., Dias, C., \& Vigário, P. D. S. (2019). Electromyographic activity of the quadriceps and gluteus medius muscles during/different straight leg raise and squat exercises in women with patellofemoral pain syndrome. J Electromyogr Kinesiol, 48, 17-23. doi:10.1016/ j.jelekin.2019.05.017

Felicio, L. R., Dias, L. A., Silva, A. P., Oliveira, A. S., \& BevilaquaGrossi, D. (2011). Muscular activity of patella and hip stabilizers of healthy subjects during squat exercises. Rev Bras Fisioter, 15(3), 206-211.

Fernandes, G. S., Parekh, S. M., Moses, J., Fuller, C., Scammell, B., Batt, M. E., . . Doherty, M. (2018). Prevalence of knee pain, radiographic osteoarthritis and arthroplasty in retired professional footballers compared with men in the general population: a cross-sectional study. Br J Sports Med, 52(10), 678-683. doi:10.1136/bjsports-2017-097503

Flaxman, T. E., Alkjaer, T., Simonsen, E. B., Krogsgaard, M. R., \& Benoit, D. L. (2017). Predicting the Functional Roles of Knee Joint Muscles from Internal Joint Moments. Med Sci Sports Exerc, 49(3), 527-537. doi:10.1249/mss.0000000000001125

Flores-León, A. F., Alonso, C., Guzmán-Venegas, R., Araneda, O. F., \& Berral de la Rosa, F. J. (2018). Centro de presión y patrones de actividad muscular durante la ejecución de una sentadilla monopodal isométrica realizada sobre una superfcie esponjosa en mujeres jóvenes sanas. Revista andaluza de medicina del deporte, 11(4), 6.

Fredericson, M., Cookingham, C. L., Chaudhari, A. M., Dowdell, B. C., Oestreicher, N., \& Sahrmann, S. A. (2000). Hip abductor weakness in distance runners with iliotibial band syndrome. Clin J Sport Med, 10(3), 169-175.

Fujisawa, H., Suzuki, H., Yamaguchi, E., Yoshiki, H., Wada, Y., \& Watanabe, A. (2014). Hip muscle activity during isometric contraction of hip abduction. Journal of Physical Therapy Science, 26(2), 187-190.

González, J. R., Moreno-Arrones, L. J. S., Bretones, A. R., \& de Villarreal Sáez, E. S. (2018). Efectos a corto plazo de un programa de entrenamiento de sobrecarga excéntrica sobre el rendimiento físico en jugadores de fútbol de élite U-16. Retos: nuevas tendencias en educación física, deporte y recreación(33), 106-111.

Grygorowicz, M., Michalowska, M., Walczak, T., Owen, A., Grabski, J. K., Pyda, A., . . Kotwicki, T. (2017). Discussion about different cut-off values of conventional hamstring-toquadriceps ratio used in hamstring injury prediction among professional male football players. PLoS One, 12(12), e0188974. doi:10.1371/journal.pone.0188974

Hae-rim, H., Jeong-ah, K., One-bin, L., Heon-seock, C., \& Chunghwi, Y. (2015). Effects of Different Types of Isometric Hip Contraction on Gluteus Medius and Tensor Fasciae Latae Activity During Squat Exercises. Physical Therapy Korea, 22(3), 71-80.

Hammami, M., Negra, Y., Billaut, F., Hermassi, S., Shephard, R. J., \& Chelly, M. S. (2018). Effects of Lower-Limb Strength
Training on Agility, Repeated Sprinting With Changes of Direction, Leg Peak Power, and Neuromuscular Adaptations of Soccer Players. J Strength Cond Res, 32(1), 37-47. doi:10.1519/jsc.0000000000001813

Hermens, H. J., Freriks, B., Disselhorst-Klug, C., \& Rau, G. (2000). Development of recommendations for SEMG sensors and sensor placement procedures. J Electromyogr Kinesiol, 10(5), 361-374.

Hislop, A. C., Collins, N. J., Tucker, K., Deasy, M., \& Semciw, A. I. (2019). Does adding hip exercises to quadriceps exercises result in superior outcomes in pain, function and quality of life for people with knee osteoarthritis? A systematic review and meta-analysis. Br J Sports Med. doi:10.1136/bjsports-2018099683

Hodges, P. W., \& Richardson, C. A. (1993). The influence of isometric hip adduction on quadriceps femoris activity. Scand J Rehabil Med, 25(2), 57-62.

Hyong, I. H. (2015). Effects of squats accompanied by hip joint adduction on the selective activity of the vastus medialis oblique. J Phys Ther Sci, 27(6), 1979-1981. doi:10.1589/ jpts.27.1979

Ireland, M. L., Willson, J. D., Ballantyne, B. T., \& Davis, I. M. (2003). Hip strength in females with and without patellofemoral pain. J Orthop Sports Phys Ther, 33(11), 671-676. doi:10.2519/ jospt.2003.33.11.671

Jimenez-Reyes, P., Samozino, P., Garcia-Ramos, A., CuadradoPenafiel, V., Brughelli, M., \& Morin, J. B. (2018). Relationship between vertical and horizontal force-velocity-power profiles in various sports and levels of practice. PeerJ, 6, e5937. doi:10.7717/peerj.5937

Kim, D., Unger, J., Lanovaz, J. L., \& Oates, A. R. (2016). The Relationship of Anticipatory Gluteus Medius Activity to Pelvic and Knee Stability in the Transition to Single-Leg Stance. Pm r, 8(2), 138-144. doi:10.1016/j.pmrj.2015.06.005

Lee, J. W. Y., Mok, K. M., Chan, H. C. K., Yung, P. S. H., \& Chan, K. M. (2018). Eccentric hamstring strength deficit and poor hamstring-to-quadriceps ratio are risk factors for hamstring strain injury in football: A prospective study of 146 professional players. J Sci Med Sport, 21(8), 789-793. doi:10.1016/j.jsams.2017.11.017

Leventer, L., Eek, F., Hofstetter, S., \& Lames, M. (2016). Injury Patterns among Elite Football Players: AMedia-based Analysis over 6 Seasons with Emphasis on Playing Position. Int J Sports Med, 37(11), 898-908. doi:10.1055/s-0042-108201

Lim, H. Y., \& Wong, S. H. (2018). Effects of isometric, eccentric, or heavy slow resistance exercises on pain and function in individuals with patellar tendinopathy: A systematic review. Physiotherapy Research International, 23(4), e1721.

Madueño, A. F., de Hoyo Lora, M., Boza, S. R., Cortés, J. M., \& Corrales, F. d. B. S. (2014). Varo y valgo de rodilla en cambios de dirección como factor de riesgo de lesión. Retos: nuevas tendencias en educación física, deporte y recreación(26), 176177.

Mathew, K., \& Pillarisetty, L. S. (2020). Anatomy, Bony Pelvis and Lower Limb, Thigh Semitendinosus Muscle. In StatPearls [Internet]: StatPearls Publishing.

McBeth, J. M., Earl-Boehm, J. E., Cobb, S. C., \& Huddleston, W. E. (2012). Hip muscle activity during 3 side-lying hipstrengthening exercises in distance runners. JAthl Train, 47(1), 15-23.

McCurdy, K., Walker, J., \& Yuen, D. (2018). Gluteus Maximus and Hamstring Activation During Selected Weight-Bearing Resistance Exercises. J Strength Cond Res, 32(3), 594-601. doi:10.1519/jsc.0000000000001893

Miao, P., Xu, Y., Pan, C., Liu, H., \& Wang, C. (2015). Vastus medialis oblique and vastus lateralis activity during a double- 
leg semisquat with or without hip adduction in patients with patellofemoral pain syndrome. BMC Musculoskelet Disord, 16, 289. doi:10.1186/s12891-015-0736-6

Millán, C. G., del Coso Garrigós, J., Vicén, J. A., del Campo, R. L., del Pozo, D. G., \& Martín, J. J. S. (2014). Cambios en la fuerza de miembros inferiores tras un mesociclo de pretemporada en futbolistas semiprofesionales. Retos: nuevas tendencias en educación física, deporte y recreación(26), 52-55.

Motomura, Y., Tateuchi, H., Nakao, S., Shimizu, I., Kato, T., Kondo, Y., \& Ichihashi, N. (2019). Effect of different knee flexion angles with a constant hip and knee torque on the muscle forces and neuromuscular activities of hamstrings and gluteus maximus muscles. Eur J Appl Physiol, 119(2), 399-407. doi:10.1007/s00421-018-4032-7

Navacchia, A., Bates, N. A., Schilaty, N. D., Krych, A. J., \& Hewett, T. E. (2019). Knee abduction and internal rotation moments increase ACL force during landing through the posterior slope of the tibia. Journal of Orthopaedic Research $₫$, 37(8), 17301742.

Nishiwaki, G. A., Urabe, Y., \& Tanaka, K. (2006). EMG Analysis of Lower Extremity Muscles in Three Different Squat Exercises. J Jpn Phys Ther Assoc, 9(1), 21-26. doi:10.1298/jjpta.9.21

Pangrazio, O., \& Forriol, F. (2016a). Epidemiology of injuries sustained by players during the 16th Under-17 South American Soccer Championship. Rev Esp Cir Ortop Traumatol, 60(3), 192-199. doi:10.1016/j.recot.2015.12.002

Pangrazio, O., \& Forriol, F. (2016b). Epidemiology of soccer players traumatic injuries during the 2015 America Cup. In Muscles Ligaments Tendons J (Vol. 6, pp. 124-130).

Park, H.-j., \& Cho, S.-H. (2016). Effect of Hip Flexion and Internal Rotation on the Hip Abductor Muscle Activity During SideLying Hip Abduction in Subjects With Gluteus Medius Weakness. Physical Therapy Korea, 23(3), 57-67.

Powers, C. M. (2003). The influence of altered lower-extremity kinematics on patellofemoral joint dysfunction: a theoretical perspective. J Orthop Sports Phys Ther, 33(11), 639-646. doi:10.2519/jospt.2003.33.11.639

Raya-González, J., Piqueras, P. G., \& Sánchez-Sánchez, J. (2018). Aplicación de un programa de fuerza con carga excéntrica en la readaptación de una lesión de ligamento lateral interno de la rodilla. Estudio de caso. Retos: nuevas tendencias en educación física, deporte y recreación, 33, 157-161.

Rio, E., Purdam, C., Girdwood, M., \& Cook, J. (2019). Isometric Exercise to Reduce Pain in Patellar Tendinopathy In-Season: Is It Effective «on the Road»? Clinical Journal of Sport Medicine, 29(3), 188-192.

Robinson, R. L., \& Nee, R. J. (2007). Analysis of hip strength in females seeking physical therapy treatment for unilateral patellofemoral pain syndrome. J Orthop Sports Phys Ther, 37(5), 232-238. doi:10.2519/jospt.2007.2439

Rowe, J., Shafer, L., Kelley, K., West, N., Dunning, T., Smith, R., \& Mattson, D. J. (2007). Hip strength and knee pain in females. N Am J Sports Phys Ther, 2(3), 164-169.

Ruas, C. V., Brown, L. E., Lima, C. D., Costa, P. B., \& Pinto, R. S. (2018). Effect of Three Different Muscle Action Training Protocols on Knee Strength Ratios and Performance. J Strength Cond Res, 32(8), 2154-2165. doi:10.1519/ jsc.0000000000002134

Spahn, G., Grosser, V., Schiltenwolf, M., Schroter, F., \& Grifka, J. (2015). Football as risk factor for a non-injury-related knee osteoarthritis - results from a systematic review and metaanalysis. Sportverletz Sportschaden, 29(1), 27-39. doi:10.1055/s-0034-1385731

Stastny, P., Lehnert, M., Zaatar, A., Svoboda, Z., Xaverova, Z., \& Pietraszewski, P. (2015). The Gluteus Medius Vs. Thigh Muscles Strength Ratio and Their Relation to
Electromyography Amplitude During a Farmer's Walk Exercise. J Hum Kinet, 45, 157-165. doi:10.1515/hukin-2015-0016

Styles, W. J., Matthews, M. J., \& Comfort, P. (2016). Effects of Strength Training on Squat and Sprint Performance in Soccer Players. J Strength Cond Res, 30(6), 1534-1539. doi:10.1519/ jsc. 0000000000001243

Suarez-Arrones, L., Saez de Villarreal, E., Nunez, F. J., Di Salvo, V., Petri, C., Buccolini, A., . . . Mendez-Villanueva, A. (2018). Inseason eccentric-overload training in elite soccer players: Effects on body composition, strength and sprint performance. PLOS One, 13(10), e0205332. doi:10.1371/journal.pone.0205332

Tang, S. F., Chen, C. K., Hsu, R., Chou, S. W., Hong, W. H., \& Lew, H. L. (2001). Vastus medialis obliquus and vastus lateralis activity in open and closed kinetic chain exercises in patients with patellofemoral pain syndrome: an electromyographic study. Arch Phys Med Rehabil, 82(10), 1441-1445. doi:10.1053/ apmr.2001.26252

Thomson, C., Krouwel, O., Kuisma, R., \& Hebron, C. (2016). The outcome of hip exercise in patellofemoral pain: A systematic review. Man Ther, 26, 1-30. doi:10.1016/j.math.2016.06.003

Trammell, A. P., \& Pilson, H. (2019). Anatomy, Bony Pelvis and Lower Limb, Tensor Fasciae Latae Muscle. In StatPearls. Treasure Island (FL): StatPearls PublishingStatPearls Publishing LLC.

Valencia, O., Cristi, I., Ahumada, D., Meza, K., Salas, R., Weinstein, A., \& Venegas, R. G. (2020). El impacto inicial con antepié incrementa la actividad muscular del gastrocnemios durante la carrera. Un estudio cuantitativo de actividad electromiográfica. Retos: nuevas tendencias en educación física, deporte y recreación(38), 271-275.

Van Hooren, B., \& Zolotarjova, J. (2017). The Difference Between Countermovement and Squat Jump Performances: A Review of Underlying Mechanisms With Practical Applications. $J$ Strength Cond Res, 31(7), 2011-2020. doi:10.1519/ jsc.0000000000001913

Wada, O., Gamada, K., Aoyama, N., Mizuno, K., \& Iwasaki, Y. (2019). A difference in rotational alignment of the tibio-femoral joint after anterior cruciate ligament reconstruction between the bone-patellar tendon-bone and semitendinosus-gracilis grafts. Clinical Biomechanics, 65, 45-50.

Waly, S. M., Asfour, S. S., \& Khalil, T. M. (2003). Effects of window size and load on estimated myoelectric signal power spectrum. Computers \& Industrial Engineering, 44(4), 595610. doi:https://doi.org/10.1016/S0360-8352(02)00237-1

Willcox, E. L., \& Burden, A. M. (2013). The influence of varying hip angle and pelvis position on muscle recruitment patterns of the hip abductor muscles during the clam exercise. J Orthop Sports Phys Ther, 43(5), 325-331. doi:10.2519/jospt.2013.4004

Wu, H. W., Tsai, C. F., Liang, K. H., \& Chang, Y. W. (2019). Effect of Loading Devices on Muscle Activation in Squat and Lunge. J Sport Rehabil, 1-19. doi:10.1123/jsr.2018-0182

Yu, C., Shao, S., Baker, J. S., \& Gu, Y. (2018). Comparing the biomechanical characteristics between squat and standing serves in female table tennis athletes. PeerJ, 6, e4760. doi:10.7717/ peerj. 4760

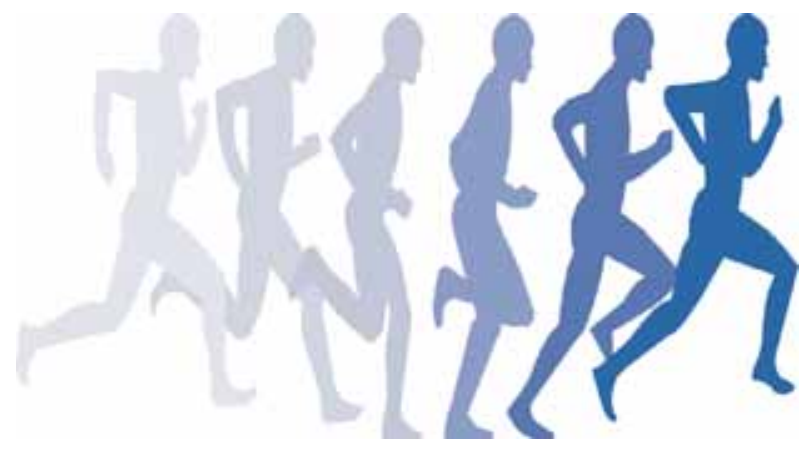

